\title{
A FENOMENOLOGIA E O DISCURSO SOBRE AS CIÊNCIAS: uma análise comparativa entre Edmund Husserl e Boaventura
}

\section{PHENOMENOLOGY AND DISCOURSE ON SCIENCES: a comparative analysis between Edmund Husserl and Boaventura}

\author{
Demóstenes Dantas Vieira ${ }^{1}$ \\ IFRN - Campus Macau: https://orcid.org/0000-0003-2196-9403
}

DOI: $10.21680 / 1982-1662.2021 v 4 n 31$ ID20174

\section{Resumo}

Este trabalho, de cunho bibliográfico e comparativo, propõe uma análise acerca de duas obras fundamentais no campo da Epistemologia/Filosofia da Ciência: A Crise das Ciências Europeias e a fenomenologia transcendental (1984), do filósofo Edmund Husserl e, Um Discurso Sobre as Ciências (2006), do sociólogo Boaventura de Souza Santos. Quanto à metodologia, este trabalho está dividido em duas partes. Na primeira, analisa-se a obra de Husserl (1984) e sua contribuição acerca da crise das ciências europeias e da fenomenologia como alternativa epistemológica. Na segunda, propõe-se uma discussão sobre o paradigma científico dominante e sobre o paradigma científico emergente, propostos por Boaventura (2006). Os resultados apontam para deslocamentos teórico-metodológicos nas bases conceituais advindas do modelo de ciência positiva que predominou tanto nas Ciências Naturais/Exatas como no início das Ciências Sociais/Humanas. Por conseguinte, a fenomenologia apresenta-se como uma possibilidade epistemológica de (re) invenção da ciência moderna, subsidiando a

\footnotetext{
1 Doutor em Linguística pela Universidade Federal do Pernambuco - UFPE; Professor-pesquisador realizando Estágio Pós-Doutoral pelo Programa de Pós-Graduação em História - PPGH oferecido pela Universidade Estadual do Oeste do Paraná - UNIOESTE;

E-mail: demostenes.vieira@ifrn.edu.br
} 
construção de um novo modelo científico.

Palavras-chave: Epistemologia da Ciência. Crise da ciência moderna. Paradigma científico.

\section{Abstract:}

This work, bibliographic and comparative, proposes an analysis of two fundamental works in the field of Epistemology/Philosophy of Science: A Crisis of European Sciences and the transcendental phenomenology (1984), by the philosopher Edmund Husserl and, A Discourse on Science (2006), by sociologist Boaventura de Souza Santos. As for the methodology, this work is divided into two parts. In the first, analyze the work of Husserl (1984) and his contribution on the economic crisis and phenomenology as an epistemological alternative. In the second, a discussion is proposed about the dominant scientific paradigm and about the emerging scientific paradigm proposed by Boaventura (2006). The results pointed to theoretical-methodological shifts in the advanced conceptual bases of the positive science model that predominate both in Natural / Exact Sciences and in the beginning of Social / Human Sciences. For example, a phenomenology presents itself as an epistemological possibility of (re) invention of modern science, subsidizing the construction of a new scientific model.

Keywords: Epistemology of Science. Crisis of modern science. Scientific paradigm.

\section{Introdução}

A partir da Epistemologia/Filosofia da Ciência, este artigo propõe uma análise comparativa entre duas obras: A Crise das Ciências Europeias e a fenomenologia transcendental ${ }^{2}$, do filósofo alemão Edmund Husserl e, Um Discurso sobre as Ciências, do sociólogo português Boaventura de Souza Santos. Academicamente, essas duas obras são fundamentais dentro dos estudos em Epistemologia/Filosofia da Ciência. A partir delas, desenvolvemos uma reflexão sobre ciência, método e objetividade.

Quanto à metodologia, este trabalho parte do método bibliográfico e

\footnotetext{
${ }^{2}$ Doravante A Crise das Ciências Europeias.
} 
comparativo, em cujo aporte teórico encontram-se as contribuições de Husserl (1984), Boaventura (2006/2018), Bourdieu et al (2007), Zilles (2008), Leão (2016), Goto (2008), dentre outros. Por sua vez, ele está dividido em duas partes. Na primeira, apresentamos a obra A Crise das Ciências Europeias e discutimos a crítica de Husserl ao modelo científico positivista adotado tanto nas Ciências Naturais como no início das Ciências Sociais e Humanas.

$\mathrm{Na}$ segunda parte, desenvolvemos uma análise da obra Um Discurso sobre as Ciências. Para tanto, analisamos as categorias de paradigma científico dominante e paradigma científico emergente propostos por Boaventura (2006). Por conseguinte, propomos a discussão sobre a ruptura com o modelo positivista nas Ciências Sociais/Humanas e sobre os deslocamentos teórico-metodológicos que emergem nas Ciências Naturais/Exatas, deslocamentos que rompem com o modelo cartesianodeterminista.

Por fim, apresentamos as considerações finais, apontando a fenomenologia como uma alternativa epistemológica ao fazer científico centrado no positivismo e no determinismo. Acreditamos que o esboço, aqui, elaborado, a partir das contribuições de Husserl (1984), de Boaventura (2006) e do conjunto bibliográfico supracitado, pode contribuir para o aprofundamento acerca da relação entre a fenomenologia husserliana e a teoria da ciência desenvolvida por Boaventura, de modo que possa também subsidiar estudantes e pesquisadores na discussão sobre a Epistemologia e/ou Filosofia da Ciência.

\section{A crise das ciências europeias e a fenomenologia}

A Crise das Ciências Europeias ${ }^{3}$, publicada pela primeira vez em 1954, é uma das mais importantes obras do filósofo alemão Edmund Husserl. A obra é fruto da conferência Die Krisis der europaischen Menschentums und die Philosophie que, em tradução livre, significa $A$ crise da humanidade europeia e a filosofia, ministrada no ano de 1935, em Viena, e no mesmo ano em Praga (LETENSKI, 2010).

Publicada postumamente, ela é a primeira obra em que o autor se posiciona com relação a um problema epistemológico da história, elaborando uma crítica

\footnotetext{
${ }^{3}$ Utilizamos como referência a versão espanhola publicada em 1984. A saber: HUSSERL, Edmund. Crisis de las ciências europeas y la fenomenologia transcendendal. México: Fólios Ediciones, 1984. Todas as citações são traduções livres realizadas pelo próprio autor.
} 
centrada na historicidade da filosofia e na epistemologia da ciência (AZEVEDO, 2001). Nela, Husserl empreende uma longa análise histórico-teleológica sobre o fazer científico e filosófico, ou melhor, sobre o fazer científico-filosófico, tendo em vista que para ele Ciência e Filosofia são indissociáveis, sendo necessário recolocar a filosofia no centro do fazer científico.

O termo kriss (crise), utilizado por Husserl (1984), nos remete ao lugar que ocupam as "ciências europeias", postuladas a partir de uma concepção de Ciência Moderna (ENGLISH, 2002). Ainda no início de sua obra, Husserl questiona se é possível falar "em uma crise das ciências tendo em vista os seus êxitos” (HUSSERL, II, 1984, p. 09). Isso porque, aparentemente, tal crise apresenta-se de forma bastante paradoxal, em um momento em que a ciência moderna se expande e se afirma como forma de conhecimento mais elaborada do que as demais formas de conhecimento produzidas pelo homem. Conforme escreve Moura (2001, p. 186), sobre o pensamento de Husserl, “apesar do sucesso das ciências positivas, existe uma crise da razão”.

Embora não seja o escopo deste trabalho, gostaríamos de destacar o lugar teórico do qual escreve Husserl, de uma filosofia acerca da razão, embora a Fenomenologia, área/movimento por ele elaborada, não possa se restringir apenas à epistemologia, no sentido etimológico da palavra, estudo do conhecimento.

De acordo com Letenski (2010, p. 13), “a Fenomenologia surge não apenas como uma filosofia, mas como um movimento de pensamento iniciado por Edmund Husserl e que exerceu grandes influências posteriores, mesmo fora do âmbito da filosofia". Pelo caráter subjetivista e não-positivo a que se propõe suas reflexões, é difícil definir o seu campo teórico (LETENSKI, 2010).

Por outro lado, têm-se materializado no decorrer do século XX diversos projetos teóricos que se colocam na perspectiva fenomenológica, a partir do que poderíamos chamar de "método fenomenológico", conforme escreve por Spiegelberg (1971). Dentre eles, podemos destacar os estudos de Merleau-Ponty, Heidegger, Habermas, Sartre, Paul Ricoeur, dentre outros.

Afunilando a discussão sobre o “método fenomenológico”, Spiegelberg (1971) afirma que ela (a fenomenologia) está mais para um exercício filosófico do que para um método de estudos empíricos. Nesse sentido, a Fenomenologia pode ser compreendida como prática do conhecimento que problematiza crenças naturalizadas sobre determinadas proposições, métodos e concepções acabadas. Desse modo, pode- 
se dizer que a Fenomenologia nos propõe um retorno à Antiguidade Clássica, período em que não havia separação entre o conhecimento filosófico e o conhecimento científico.

Tendo em vista os diversos projetos de estudo em fenomenologia e as considerações já realizadas, gostaríamos de definir, em termos teóricos, a concepção de Fenomenologia em que nos baseamos, como "um movimento renovador da filosofia" que busca "estabelecer a Filosofia como ciência" a partir de "um método de rigorosa validez" (LETENSKI, 2010, p. 13). Desse modo, pode-se dizer que a fenomenologia propõe a restauração do “conceito de Filosofia, degradado pelo Positivismo que a espoliou e fez dela uma mera 'serva' da ciência. [...] como uma reação ao espírito reducionista e dominador do positivismo científico" (LETENSKI, 2010, p. 13).

No conjunto de sua obra, em especial a Crise das Ciências Europeias, Husserl (1984) apresenta a ciência positiva como um modelo de rigorosidade científica, tanto no que se refere ao método quanto à sua própria natureza. Pautada no racionalismo, ela se coloca como única forma de se chegar à verdade, tendo em vista o rigor dos métodos e confiabilidade dos conceitos pela própria ciência elaborados. De acordo com Leão (2016, p. 32):

o cientificismo que se caracterizou como uma forma de pensar derivada do positivismo, considerou o método científico como único e definitivo conhecimento da realidade - na esfera da ciência poderíamos encontrar solução para todos os problemas, sejam eles de natureza física ou social. Hoje se discute ciência única e infalível como um mito.

Para atingir esse status, a ciência moderna precisou dissociar-se de outras formas de conhecimento, como a Religião, o Mito, a Filosofia e a Arte. Essa separação, a princípio relevante, distanciou a filosofia da ciência, tornando-se menos crítica em si mesma e mais instrumentalizada com relação à compreensão da natureza (LEÃO, 2016).

Nesse sentido, a passagem da Idade Média para a Idade Moderna caracteriza-se pela separação entre Filosofia e Ciência, através da qual o "entendimento de método passou a ser cada vez mais como instrumental" e como uma "condição necessária para se estabelecerem os limites, a demarcação, entre o que era e o que não é científico" (LEÃO, 2016, p. 33). Dessa forma, “o método substituiu o mito, as religiões, pela 
racionalidade, pela lógica, pela objetividade, a fim de captar e manipular uma realidade a partir de uma base experimental" (LEÃO, 2016, p. 33).

Em vista disso, elencamos duas consequências da separação entre a Filosofia e Ciência. A primeira refere-se ao fato de que "o método eliminou as possibilidades de uma crítica de seus procedimentos e de uma análise de seus pressupostos filosóficos, da concepção de homem e de mundo que o orienta” (LEÃO, 2016, p. 34). A segunda nos remete ao afastamento da ciência de quaisquer concepções teleológicas, não havendo a necessidade de se questionar a finalidade da produção do saber científico (LEÃO, 2016).

A perspectiva husserliana traz à baila a filosofia como elemento intrínseco à ciência, sendo ela própria uma "ciência de rigor”. Nesse sentido, não se trata de renunciar "a cientificidade, seu método e legitimidade" (HUSSERL, 1984, II, p. 11), mas de submetê-la a uma crítica, à sua origem e pressupostos.

A crítica de Husserl (1984) baseia-se, a priori, na (re) colocação da filosofia no centro do desenvolvimento científico. Isso significa também o desenvolvimento de uma teoria científica do homem e para o homem. Dessa forma, Husserl tece uma crítica a uma ciência moderna desvinculada do conhecimento humano, tendo em vista que, segundo ele, "a ciência de fatos puros e simples produzem homens que só percebem puros e simples fatos" (HUSSERL, 1984, II, p. 11).

Por conseguinte, a ciência moderna desvinculou-se de uma teleologia humana, excluindo de sua exegese "a inópia da vida humana". Postulando uma ciência que “não tem nada a dizer", tendo em vista que "descarta os problemas mais latentes do homem, que, em um tempo de tormentos, sente-se à deriva do destino: as questões sobre o sentido e o não-sentido da existência humana” (HUSSERL, 1984, II, p. 11-12).

Husserl (1984) coloca a crise das ciências no interior de uma crise da humanidade, bastante evidente no niilismo europeu que tenta apagar/desconstruir todo um constructo filosófico ocidental acerca da existência humana. Conforme escreve Moura (2011, p. 187), o que se coloca em questão é a relação entre o saber científico e “o significado da existência humana”. De acordo com Zilles (2008, p. 30) "na fase da crise Husserl indaga o porquê do fracasso das ciências, perguntando pela origem dessa crise e redescrevendo a trajetória da razão ocidental. Constata que, pela matematização, as ciências se afastam do mundo da vida e da teleologia que fundamenta a cultura ocidental". 
Nesse sentido, a ciência moderna destitui-se do sentido “ominocompreensivo" de filosofia como conhecimento acerca da totalidade humana, como totalidade do ser. Por conseguinte, as diversas ciências, fragmentos modernos de uma filosofia do homem, por meio de um axioma positivo, anularam os "problemas da razão - seja no tocante ao problema do conhecimento, da ação ética, do sentido da história, de deus, da imortalidade, da liberdade etc." (AZEVEDO, 2001, p. 53).

Em vista disso, pode-se dizer que o modelo positivista de ciência não satisfaz às análises da vida social e humana, tendo em vista que ele restringe a atividade científica aos experimentos, aos laboratórios, ao determinismo, a fatos metodologicamente isolados. Desse modo, "o positivismo guilhotina a filosofia" (HUSSERL, VII, 1984, p.7). Não se trata, entretanto, de invalidar os avanços da ciência moderna. Pelo contrário, a análise segue na direção de pensar como essa ciência pode deslocar-se ao encontro de uma filosofia do homem, da sua existência, do mundo da vida (Lebenswelt). À vista disso:

O caminho (método) para a construção de uma nova ciência do mundodavida será definido a partir da redução (com seus sentidos) que possibilitará a primeira e fundamental "suspensão", ou seja, a epoché das ciências objetivas. [...] é pela analítica promovida pela epoché que será possível dar o "primeiro passo" para a conquista do mundo-da-vida (Lebenswelt) (GOTO, 2008, p.151).

Voltar-se ao mundo da vida pressupõe alguns movimentos teóricos:

1) A experiência antepredicativa: o mundo natural, mundo objetivo e as idealizações da ciência positiva nos forjam para uma experiência predicativa, do qual os valores, as crenças determinam nossos julgamentos a priori. Portanto, a experiência antepredicativa constitui uma experiência originária antes do julgamento.

2) Nesta condição, emerge também, um mundo não lógico-teórico cientificamente.

3) Com efeito, o mundo-da-vida ganha seu caráter pré-teórico, ultrapassando o saber científico já constituído

4) Portanto, seu caráter é pré-científico pois não se constitui das idealidades lógicas das ciências positivas, mas sim, de uma experiência originária e dos vários sentidos de mundo dos homens entre homens, dele com as coisas, com os animais (GOTO, 2008 Apud FERREIRA, 2005).

Pensar o mundo da vida tarefa evidentemente fenomenológica, é recuperar a experiência e o saber para além de um modelo determinista e cartesiano. É compreender a relação entre sujeito e formação do conhecimento, entre a ciência e a 
existência humana, fazendo uma ponte entre o saber científico e a "cientificidade" de uma episteme humana, não apenas lógica, não determinista, não positiva, mas repleta de verdades originárias dos diversos sentidos do homem. Nesse sentido, a fenomenologia coloca o homem no centro da ciência e a filosofia da existência no centro do método.

Isso não significa dizer que a fenomenologia coloca a margem o rigor da ciência, pelo contrário, traz à baila um rigor epistemológico que nos remonta à ciência nos moldes clássicos em que não havia separação entre filosofia e saber, onde toda e qualquer produção estava/está ligada à humanidade e a uma reflexão ontológica da vida.

\section{Boaventura e a crise da ciência: alguns apontamentos}

Em Cassirer (2000) a ciência é compreendida como o tipo de conhecimento mais importante da evolução humana e como tema mais importante para a filosofia do homem. Para Cassirer (2006) a ciência, juntamente com outros produtos simbólicos, como a linguagem, o mito, a magia, a cultura, a religião, a filosofia e a arte, é elemento fundamental na composição do homem como nós o conhecemos hoje. Separar a ciência do mundo da vida é, portanto, retirar do homem algo que é inerente à sua condição, a razão.

A crise da ciência discutida por Husserl (1984) é antes uma crise da humanidade, sobre o humano esquecido entre fórmulas, laboratórios e experiências quantificáveis. As generalizações impostas ao método científico, tais como o rigorismo, o objetivismo, a neutralidade e a quantificação, perduraram desde o século XVI com a sistematização do método científico realizada Galileu Galilei que, por sua vez, recebeu a alcunha de Pai da Ciência Moderna.

A ciência positiva entende que só podemos identificar as leis da natureza e da vida social se adotarmos uma metodologia rigorosa, caracterizada também pela objetividade e neutralidade. Ela parte da crença de que ao analisar um objeto repetidas vezes, reproduzindo as condições de análise, utilizando-se do mesmo método, objetivo e rigor, os resultados de uma e de outra pesquisa seriam os mesmos. Tal modelo conduziu a produção científica por séculos, influenciando não apenas Ciências Exatas/Naturais, mas também as Ciências Sociais e Humanas, principalmente, na origem delas. Em vista disso, tomaremos como exemplo a origem da Sociologia, da 
Linguística e da Psicologia, de modo que possamos entender o impacto da ciência positiva nas Ciências Sociais e Humanas.

As Regras do Método Sociológico, publicada pela primeira vez em 1895, é considerada a obra que deu origem à Sociologia, isso porque ela é a primeira a propor a sistematização do método sociológico, atribuindo à Sociologia o rigor necessário para receber o status de ciência em sua época. Durkheim (1999) defendia que assim como as ciências naturais podiam descrever as leis da natureza, também se poderia definir as leis da sociedade e as regras de seu funcionamento.

Segundo Boaventura (2018, p. 42-43), “para estudar os fenómenos sociais como se fossem fenómenos naturais [...] como pretendia Durkheim, o fundador da sociologia académica, seria necessário reduzir os factos sociais às suas dimensões externas, observáveis e mensuráveis”. Ao estudar o aumento das taxas do suicídio, por exemplo, Durkheim (2004) propõe a análise de dados que expliquem o fenômeno, por sua vez, ele opta por dados mensuráveis nos quais possam ancorar-se, tais como estado civil, religião, sexo, família, situação econômica, etc. Por outro lado, suplanta questões subjetivas que poderiam ser facilmente coletadas nas cartas suicidas, documento comum até os dias de hoje.

Saussure (2006), no Curso de Linguística Geral, obra que deu origem à Linguística Moderna, também formulou um modelo de ciência bastante cartesiano, centrado numa concepção de língua como estrutura e nas regras do seu funcionamento, privilegiando a língua (langue) como fato social em detrimento da análise da fala (parole), aspecto que ele considerou individual, portanto, subjetivo e de difícil mensuração. Sobre o legado de Saussure e sobre o modelo de ciência adotado por ele, Vieira (2019, p. 14) escreve que:

O maior legado deixado por Saussure é principalmente metodológico, embora não possamos negar a sua capacidade de abstração e (re)elaboração de toda uma teoria linguística que o antecedeu. Saussure se opõe à visão tradicional de Hermann Paul, segundo a qual a abordagem histórica seria a mais adequada para os estudos acerca da linguagem. Saussure (2006) propõe que a língua é um sistema relativamente autônomo, regido por regras de funcionamento e aproxima-se do paradigma científico moderno (até certo ponto determinista), ao considerar que a língua deve ser analisada isoladamente, excluindo-se as influências externas e, por assim dizer, a fala (parole). 
Assim como ocorreu com a Sociologia, para o estabelecimento da Linguística como Ciência era necessário que se elaborasse um método de análise que fizesse jus ao modelo de ciência positiva centrada na rigorosidade, na objetividade e na neutralidade científica. Talvez, por isso, o corte metodológico saussuriano tenha deixado os estudos acerca do sujeito e da fala à margem da Linguística que, por sua vez, priorizou aspectos da vida social que pudessem ser, até certo ponto, mensurados, neste caso, associados à estrutura da língua. Sobre essa questão, Vieira (2019, p. 13 14) acrescenta que "o corte saussuriano (pensando aqui o seu objeto de estudo, a langue) e a tomada da estrutura como ponto de partida dos estudos da linguagem (o método), possibilitou o estabelecimento da Linguística como ciência”.

A Psicologia, no princípio, também adotou um modelo cartesiano. Ela se consolida como ciência nos anos 80, principalmente, a partir dos trabalhos experimentais de Wilhelm Wundt, considerado o seu fundador.

Em obra intitulada Princípios de Psicologia Fisiológica, Wundt (1910) propôs a demarcação dos princípios da psicologia como uma nova ciência. Para tanto, o autor situa a psicologia no domínio das ciências naturais. Dentre as muitas pesquisas, Wundt elaborou uma teoria das sensações e da percepção baseada em estímulos e resposta, registrando aspectos ligados à variação física, tais como alteração dos batimentos cardíacos, da respiração, etc.

Como é possível perceber, as Ciências Sociais e Humanas adotaram o modelo cartesiano, embora seja notório que diversos pesquisadores irão deslocá-las para um modelo compreensivo e interpretativo que não cabe nos moldes da ciência positiva. De acordo com Boaventura (2018, p. 43), as Ciências Sociais e Humanas têm adotado uma concepção "antipositivista e assenta na tradição filosófica da fenomenologia e nela convergem diferentes variantes", desde Max Weber, com uma visão mais moderada, até Peter Winch com uma abordagem bastante extremista (BOAVENTURA, 2018).

De certo modo, as Ciências Sociais passaram por processos de reformulação teórico-metodológica, assumindo hoje um paradigma dissonante com relação ao positivismo, isso se deve, em parte, ao reconhecimento de que o seu objeto, o homem, é subjetivo.

Por outro lado, têm-se produzido diversas perspectivas teóricas nas Ciências Exatas/Naturais que problematizam o modelo positivista. Em Um Discurso sobre as 
Ciências, Boaventura (2006) discute a chamada "crise das ciências" e discorre sobre dois paradigmas científicos: um hegemônico, baseado na ciência positiva e um emergente, ainda em construção. Pode-se dizer que o modelo positivo de ciência dá lugar a uma concepção “pós-moderna ou novo-paradigmática”, conforme escreve Vasconcellos (2002, p. 68).

Evidentemente, a concepção ou paradigma emergente vem-se materializando a partir de estudos variados, tais como a queda do rigorismo matemático, as proposições indecifráveis e/ou teoremas da incompletude de Godel; a teoria da relatividade de Einstein que coloca em dúvida as noções de espaço e tempo; a mecânica quântica e a microfísica de Heisenberg e Bohr com a impossibilidade de observar e medir um objeto sem interferir nele, dentre outras (BOAVENTURA, 2006).

Boaventura (2006) discorre ainda sobre alguns deslocamentos epistemológicos produzidos pelo paradigma emergente, dos quais destacamos: 1. Toda ciência natural é também ciência social; 2. Todo conhecimento é local e universal; 3. Todo conhecimento é autoconhecimento; 4. Todo conhecimento científico visa constituir-se em senso comum.

Ao enunciar que toda ciência natural é também ciência social, Boaventura (2006) suscita a tese de que a Ciência da Natureza, compreendida como produto simbólico, também é uma ciência social. Isso implica dizer que a condição humana não é multifacetada, dividida entre o natural e o social, pelo contrário, o homem é um ser integral, constituído de diversos aspectos inter/multi/transrelacionais.

Por sua vez, ao afirmar que todo conhecimento é local e total, Boaventura (2006) tece uma crítica ao processo de fragmentação, parcelamento ou superespecialização do conhecimento, característica bastante forte na ciência positivista. Sobre isso, Boaventura (2006, p. 47) argumenta que:

Os males desta parcelização do conhecimento e do reducionismo arbitrário que transporta consigo são hoje reconhecidos, mas as medidas propostas para os corrigir acabam em geral por os reproduzir sob outra forma. Criam-se novas disciplinas para resolver os problemas produzidos pelas antigas e por essa via reproduz-se o mesmo modelo de cientificidade

Nesse contexto, o paradigma emergente evidencia problemas que não podem ser compreendidos por uma dada disciplina ou parcela do saber científico. Isso porque sua resposta esbarra nas fronteiras que demarcam o espaço entre esta e aquela 
especialidade.

Dando continuidade, a noção proposta por Boaventura (2006) de que todo conhecimento é autoconhecimento aponta para uma reflexão acerca da objetividade e neutralidade científica. Segundo Boaventura (2006), o objeto de investigação seria de certa forma, a continuação do homem, tendo em vista que o homem se (re)conhece através dele. Nesse sentido, a o conhecimento é produzido de forma direta (sobre o objeto) e indireta (sobre o sujeito). Nessa perspectiva, "a ciência é autobiográfica" (BOAVENTURA, 2006, p. 52). Isso significa dizer que:

No paradigma emergente, o caráter autobiográfico e autoreferenciável da ciência é plenamente assumido. A ciência moderna legou-nos um conhecimento funcional do mundo que alargou extraordinariamente as nossas perspectivas de sobrevivência. Hoje não se trata tento de sobreviver como de saber viver. Para isso é necessário uma outra forma de conhecimento, um conhecimento compreensivo e íntimo que não nos separe e antes nos uma pessoalmente ao que estudamos. A incerteza do conhecimento, que a ciência moderna sempre viu como limitação técnica destinada a sucessivas superações, transforma-se na chave do entendimento de um mundo que mais do que controlado tem de ser contemplado (BOAVENTURA, 2006, p. 54).

Endossando essa perspectiva, Bourdieu et al (2007, p. 60) escrevem que até as operações mais "elementares" e mesmo as operações "mais automáticas do tratamento da informação" aludem a escolhas epistemológicas e mesmo a uma teoria sobre o objeto. Ao que nos parece, os autores tratam a neutralidade científica a partir do princípio de não consciência ${ }^{4}$, visto que a subjetividade do pesquisador adentra as operações por ele realizadas, mesmo inconscientemente. 0 princípio da não consciência que, por sua vez, problematiza a neutralidade científica, se coloca como "uma nova caução à ilusão positivista", visto que a subjetividade entra em jogo desde a escolha do objeto pelo pesquisador até as demais escolhas metodológicas realizadas por ele (BOURDIEU et al, 2007, p. 55).

Por fim, o último aspecto levantado por Boaventura (2006) acerca do paradigma emergente, é a compreensão de que todo conhecimento científico visa constituir-se em senso comum. Em termos empíricos, isso significa que o conhecimento científico, nas mais diversas áreas, deve se constituir de um saber comum, acessível ao cidadão. Nesse sentido, propõe-se uma ruptura com a dicotomia que coloca o cientista e a

\footnotetext{
${ }^{4}$ Expressão usada por Bourdieu et al (2007) para designar escolhas inconscientes no que se refere aos procedimentos metodológicos.
} 
ciência num lugar inalcançável e o homem comum no lugar da ignorância, por sua vez, incapaz de compreender aquilo que se diz e se produz cientificamente. Pelo contrário, a ciência deve cumprir papel importante na vida social, constituindo-se como senso comum à medida que se torna acessível ao cidadão (BOAVENTURA, 2006).

De certo modo, a concepção de senso comum trazida por Boaventura (2006) se assemelha a uma arena em que os diversos saberes - científico, popular, religioso, filosófico, dentre outros - se materializam. Por esse motivo, a discussão sobre ciência a partir do paradigma emergente pressupõe uma reflexão sobre as práticas sociais e, portanto, uma ruptura com o modelo de produção científica restrito àqueles que a produzem.

Tendo em vista as considerações já realizadas, a relação entre as proposições de Boaventura (2006) acerca da ciência e a discussão sobre os paradigmas dominantes e emergentes dialogam com a obra de Husserl (1984) acerca da ciência positiva e da fenomenologia como crítica da razão. Por assim dizer, essas duas obras assumem papel importante no que tange à Epistemologia/Filosofia da Ciência, contribuindo, cada uma em seu tempo, com a discussão acerca da Ciência Moderna/Positiva, das suas bases epistemológicas, crenças e representações.

\section{Considerações finais}

A bibliografia consultada aponta para a filosofia como elemento intrínseco ao fazer científico. As duas obras analisadas, Husserl (1984) e Boaventura (2006), trazem reflexões importantes sobre as bases conceituais da Ciência Moderna e sobre a emergência de novos paradigmas acerca do fazer científico que, do ponto de vista fenomenológico, coloca a filosofia no centro do seu fazer, não à sua margem.

As análises realizadas, tanto da obra de Husserl (1984), como da obra de Boaventura (2006), suscitam a superação da dicotomia entre as Ciências Exatas/Naturais e as Ciências Sociais e Humanas, de modo que se possa entender que toda ciência natural é também uma ciência social e humana.

Com relação à objetividade e à neutralidade científica, os autores estudados convergem no entendimento de que toda ciência (seja ela natural ou social) é resultado de processos subjetivos, tendo em vista que o fazer científico, das operações mais "elementares”, até aquelas mais automáticas e complexas, aludem a escolhas subjetivas. Isso implica também numa compreensão de ciência como uma 
forma de conhecimento ligado ao mundo da vida (Lebenswelt), sendo, portanto, uma prática que se desenvolve de forma direta sobre o homem (que a realiza) e de forma indireta sobre o objeto estudado.

Para (não) concluir, a obra de Husserl (1984) e de Boaventura (2006) desenvolvem uma discussão importante para a Epistemologia/Filosofia da Ciência, problematizando as bases conceituais do conhecimento científico - positivista e cartesiano - e, apresentando alternativas epistemológicas ao modelo dominante de ciência. Por sua vez, a profundidade das duas obras, aqui, analisadas, faz jus a múltiplas e fenomenológicas interpretações, tendo em vista o campo em que elas fincam os pés, o fazer científico.

\section{Referências}

AZEVEDO, Erico de Lima. A Crise das Ciências Europeias e a Fenomenologia Transcendental" de Edmund Husserl: uma apresentação. Programa de PósGraduação em Filosofia. PONTIFÍCIA UNIVERSIDADE CATÓLICA DE SÃO PAULO - PUC/SP, 2011.

BOAVENTURA, de Souza Santos. Um Discurso Sobre as Ciências. 15ª Ed. Porto: Edições Afrontamento, 2006.

BOURDIEU, Pierre et al. A Construção do Objeto. In: Ofício de Sociólogo. Metodologia da Pesquisa na Sociologia. 6 ed. Petrópolis: Vozes, 2007, p.45-72.

- Construindo as Epistemologias do Sul: Antologia Esencial. Volume I: Para um pensamento alternativo de alternativas / Boaventura de Sousa Santos. Ciudad Autónoma de Buenos Aires: CLACSO, 2018.

CASSIRER, Ernest. Filosofia das formas simbólicas. São Paulo: Martins Fontes, 2000.

DURKHEIM, Émili. As regras do método sociológico. Tradução de Paulo Neves. $2^{\circ}$. ed. São Paulo: Martins Fontes, 1999.

O Suicídio. São Paulo: Martins Fontes, 2004.

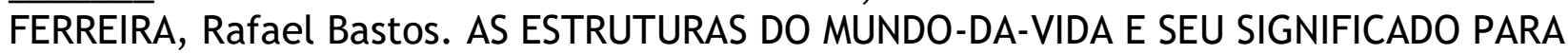
A GEOGRAFIA. Anais XI Encontro Nacional da ANPEG. Disponível em: <http://www.enanpege.ggf.br/2015/anais/arquivos/17/501.pdf>. Acesso em $10 \mathrm{de}$ julho de 2017.

GEERTZ, Clifford. A Interpretação das Culturas. Rio de Janeiro: Ltc, 2008.

GOTO. Tommy Akira. Fenomenologia, mundo-da-vida e crise das ciências: a necessidade de uma geografia fenomenológica. Geograficidade, v.3, n.2, Inverno 2013.

HUSSERL, Edmund. Crisis de las ciências europeas y la fenomenologia transcendendal. México: Fólios Ediciones, 1984.

LEÃO, Lourdes Meireles. Conhecimento, Ciência e Método. In: Metodologia do estudo e pesquisa: facilitando a vida de estudantes, professores e pesquisadores. Petrópolis: Vozes, 2016.

LETENSKI, IRINEU. EDMUND HUSSERL E A CRISE DAS CIÊNCIAS EUROPEIAS 
(Dissertação). Programa de Pós-Graduação em Filosofia. UNIVERSIDADE FEDERAL DO PARANÁ - UFPR, 2010.

MERLEAU-PONTY, Maurice. Ciências do Homem e Fenomenologia. São Paulo: Editora Saraiva, 1973.

MORIN, E. O paradigma perdido: a natureza humana. Lisboa: Europa-América, 1973

MOURA, Carlos Alberto Ribeiro. Racionalidade e crise: estudos de história da filosofia moderna e contemporânea. São Paulo: Discurso Editorial e Editora da UFPR, 2001.

SAUSSURE, F. Curso de linguística geral. $27^{\mathrm{a}}$ ed. São Paulo: Cultrix, 2006.

SPIEGELBERG, H. The Phenomenological Movement. A historical introduction. The Hague: Martinus Nijhoff, 1971.

VASCONCELLOS, Maria José Esteves de. Delineando o paradigma tradicional da ciência. In: Pensamento sistêmico: o novo paradigma da ciência. Campinas: Papirus, 2002.

VIEIRA, DEMÓSTENES DANTAS. DA LINGUÍSTICA SAUSSURIANA À ANÁLISE DO DISCURSO: ALGUNS DESLOCAMENTOS. Revista de Letras Norte@mentos. Dossiê Temático: Estudos Linguísticos em foco, Sinop, v. 12, n. 30, p. 11 -24, out. 2019. Disponpivel em:<http://sinop.unemat.br/projetos/revista/index.php/norteamentos/article/view/ 3726/2581>. Acesso em 18 de março de 2020.

WEBER, Max. A "objetividade" do conhecimento na ciência social e na ciência política. In: Metodologia das Ciências Sociais. Parte 1. Tradução de Augustin Wernet. 4. ed. São Paulo: Cortez; 2001. p. 107-154.

WUNDT, W. Principles of physiological psychology. London: Swan Sonnenschein \& Co, 1910.

ZILLES, Urbano. A Fenomenologia husserliana como método radical. In: HUSSERL, Edmund. A crise da humanidade europeia e a filosofia. Introd. e Trad. Urbano Zilles. - 3. ed. Porto Alegre: EDIPUCRS, 2008. 